\author{
Maha T A1-Saffar ${ }^{1}$ \\ BDS, MSc (Lectu) \\ Tahani A Al-Sandook ${ }^{1}$ \\ BDS, PhD (Prof)
}

Mohammad S Suleiman BDS, MSc (Lectu)

\section{Protective Effect of Topical Ibuprofen Against Dry Socket}

\author{
1 Department of basic science \\ College of Dentistry, University of Mosul
}

Department of oral and maxilofacial surgery

College of Dentistry, University of Mosul

\begin{abstract}
Aims: To assess the clinical effect of topical preventive measures on the incdence of alveolar osteitis (dry socket) by inserting (either gelfoam sooked with ibuprofen suspension, or gelfoam sooked with metronidazole suspension, or gelfoam alone) in the extraction socket following removal of lower posterior teeth. Materials and Methods: One hundred eighty patients were included in the present study, (86) males and (94) females aged between 13-65 years, they were divided randomly into four treatment groups. The first group included 43 patients (control - ve), who received no topical medication following extraction. Whereas, in the second (control +ve) group which comprised 44 patients, gelfoam alone was inserted in the socket of extraction. While in the third group, gelfoam impregnated with metronidazole suspension was placed in the extraction socket, this group included 50 patients. However 43 patients treated in the fourth group, where gelfoam sooked with ibuprofen suspension was packed into the socket following extraction. Results: Comparison of the incidence of dry socket among the study groups were performed. Statistical analysis revealed that the prevalence of dry socket were significantly affected by the sex and tooth number. The topical application of ibuprofen provided a higher incidence of reduction in dry socket followed by metronidazole, while the application of gelfoam alone increased the incidence of this complication when compared with the remaining groups. Conclusion: This study showed that the topical ibuprofen suspension can be used as a prophylactic method to reduce the incidence of dry socket following removal of lower posterior teeth.

Key Words: Dry socket, alveolar osteitis, topical ibuprofen.

Al-Saffar MT, Al-Sandook TA, Suleiman MS. Protective Effect of Topical Ibuprofen Against Dry Socket. Al-Rafidain Dent J. 2008; 8(2): 136-143.

Received: 5/7/2007

Sent to Referees: 5/7/ 2007

Accepted for Publication: 19/8/2007
\end{abstract}

\section{INTRODUCTION}

Dry socket (DS) or acute alveolar osteitis is an annoying, very painful and distressing condition for a patient who had recently undergone a tooth extraction. ${ }^{(1,2)}$ The incidence rates of dry socket that have been reported by many researchers ${ }^{(3-9)}$ range between $4-24 \%$. This complication of tooth extraction has plagued oral surgeons since the practice of exodontia began ${ }^{(4)}$. Metin et al., ${ }^{(3)}$ stated that alveolar osteitis is a common complication following the removal of permanent teeth espicially lower posterior teeth The pathognomnic features of dry socket are abscence of the normal clot from the extraction socket, the bony walls of which are denuded and exqusitely sensitive to even gentle probing. Halitosis (which occurs due to accumulation of food debris and disintegrated blood clot) is invariably present, fever is seldom seen ${ }^{(6,7)}$. Several investigators $^{(6-9)}$ mentioned that "there is no definitive cause for dry socket", but many predisposing factors have been implicated, including frequent changing of pressure-dressing gauze, frequent mouth rinsing, an underlying infection, smoking, the use of oral contraceptive pills, undue surgical trauma and excessive amount of local anaesthesia (which inturn reflect a high concentration of a vasoconstrictor agent). This mean that dry socket probably arises as a result of a complex 
interaction between surgical trauma, local bacterial infection and various systemic factors, for example diabetes mellitus.

The occurance of dry socket as a postoperative problem is very important for both the patient and the surgeon since the former will need multiple (painful) return-office visits, in addition to the cost of management which means an economic loss ${ }^{(10)}$. Therefore, several studies ${ }^{(11-15)}$ indicated that prevention is always the method of choice to reduce the incidence of dry socket. These include the use of chlorhexidine mouth wash, the placement of medicated packing into the extraction socket and the prophylactic use of metronidazole and lenampicillin, yet no single method has gained a universal success or acceptance, although a large number of practitioners continue to use " their own methods " in an attempt to reduce the incidence of this complication $^{(16-17)}$.

The purpose of the present study was to evaluate the clinical efficacy of topical preventive measures (using gelfoam sooked with ibuprofen suspension, gelfoam sooked with metronidazole suspension, and gelfoam alone in the extraction socket following removal of lower posterior teeth) on the incdence of alveolar osteitis (dry socket).

\section{MATERIALS AND METHODS}

This study was implemented over a period of six months at the Department of Oral and Maxillofacial Surgery. Dental Teaching Hospital of College of Dentistry, University of Mosul. One hundred eighty patients aged between 13-65 mean age (39 years) and of both genders (86 males and 94 females) were included. All patients were informed about the purpose of the study, every patient should be medically fit, did not use any medication within the last 72 hours for dental or medical purposes and had no contraindication to the use of metronidazole or ibuprofen. Pregnant or lactating women and smoker patients were excluded from the study. Only patients who required extraction of one of the lower posterior teeth $\left(1^{\text {st }}\right.$ or $2^{\text {nd }}$ or $3^{\text {rd }}$ molar) were included in the study. Patients were randomly distributed into four groups as follows:-

Group I: which served as a control negative, it included (43) patients who received no topical medication following

Group II: (4ex)traetiients in this group were used as a control positive (Gelfoam alone was placed in the extraction socket).

Group III: (50) patients were included in this group. Gelfoam impregnated with metronidazole suspension (40 $\mathrm{mg} / \mathrm{ml}$. Gulf Pharmacutical Industry. UAE) was inserted in the socket following extraction.

Group IV: This group comprised (43) patients, here gelfoam sooked with ibuprofen suspension (20 $\mathrm{mg} / \mathrm{ml}$. Asia Pharmacutical Industry. Syria) was packed into the socket following extraction.

Special case sheet was designed for the study, it included personal informations, no. of extracted tooth and type of treatment for each patient

(Figure).
Patient name:
Age:
Extracted tooth
First molar: Second molar
Gp I: No treatment (control -ve):
Gp II: Gelfoam alone(control +ve):
Gp III: Gelfoam with metronidazole:
Gp IV: Gelfoam with ibuprofen :
Dry socket:
Yes:
No:
Third molar :

Sex:

Figure : (Case sheet) 
All patients were operated on under local anaesthesia which was achieved by inferior alveolar, lingual and long buccal nerve block using $(1.8 \mathrm{ml})$ of $2 \%$ lignocaine hydrochloride with 1:80000 adrenaline $^{(18)}$. (Kwang Myung Pharm. Co, Ltd, Kyunggi-do, Korea). All extractions were performed by the same surgeon, close (intra-alveolar) extraction method was used for the removal of teeth. Any patient who had a tooth indicated for extraction using open (transalveolar) method was excluded from the study. Following extractions, all patients were given paracetamol tablets (500mg qid.) as analgesic for five consecutive days . Cheque up (for the presence of dry socket or not) was performed 3 days after extraction. The diagnosis of dry socket was done according to the criteria specified by Blum: ${ }^{(19)}$ These include post- operative pain in and around the extraction site which increases in severity at any time between 1 and 3 days after extraction accompanied by partially or totally disintegrated blood clot within the alveolar socket with or without halitosis.

Statistical analysis was performed using Pearson Chi-square test. Significant difference was recorded at $(p \leq 0.01)$ level.

\section{RESULTS}

The total number of patients involved in the study was 180 , from them 45 patients $(25 \%)$ developed dry socket, 29 males (16.1\%) and 16 females $(8.9 \%)$. Statistical analysis revealed significant difference in relation to sex, this reflects a strong correlation between sex and dry socket as shown in Table (1).

Table (1): Distribution of patients and

Pearson Chi-aquare test in relation to the sex and presence of dry socket

\begin{tabular}{|c|c|c|c|c|}
\hline \multirow{3}{*}{ Sex } & \multicolumn{4}{|c|}{ Dry socket } \\
\cline { 2 - 5 } & \multicolumn{2}{|c|}{ Present } & \multicolumn{2}{c|}{ Not present } \\
\cline { 2 - 5 } & No. & $\mathbf{\%}$ & No. & $\mathbf{\%}$ \\
\hline Male & 29 & 16.1 & 57 & 31.7 \\
\hline Female & 16 & 8.9 & 78 & 43.3 \\
\hline Total & 45 & 25 & 135 & 75 \\
\hline \multicolumn{2}{|c|}{ Pearson $\chi^{2}=6.680, \mathrm{df}=1$}
\end{tabular}

Table (2) explained the results concerning tooth number and the incidence of dry socket, a highly significant difference was observed. The higher percentage of dry socket was recorded after lower third molar extraction (24 patients) followed by second molar (12 patients), while the least incidence for this complication was observed following lower first molar removal (9 patients only).

Table (2): Distribution of patients and Pearson

Chi-aquare test in relation to the tooth number and presence of dry socket

\begin{tabular}{|c|c|c|c|c|}
\hline \multirow{2}{*}{ Tooth no. } & \multicolumn{4}{|c|}{ Dry socket } \\
\cline { 2 - 5 } & \multicolumn{2}{|c|}{ Present } & \multicolumn{2}{c|}{ Not present } \\
\cline { 2 - 5 } & $\mathbf{N o .}$ & $\mathbf{\%}$ & No. & $\mathbf{\%}$ \\
\hline $\mathbf{1}^{\text {st }}$ molar & 9 & 5 & 61 & 33.9 \\
\hline $\mathbf{2}^{\text {nd }}$ molar & 12 & 6.7 & 41 & 22.8 \\
\hline $3^{\text {rd }}$ molar & 24 & 13.3 & 33 & 18.3 \\
\hline Total & 45 & 25 & 135 & 75 \\
\hline Pearson $\chi^{2}=14.557, \mathrm{df}=2$ \\
\multicolumn{3}{l}{}
\end{tabular}


Regarding age, the peak prevalence of dry socket was seen in the (20-29) years age group which recorded 16 cases of dry socket, followed by (30-39) years age group where 12 dry sockets had been observed. While the least incidence of dry socket was recorded (only 3 cases) for the(13-19) years age group. However, no significant differences among the age groups (in regard to the presence of dry socket ) were observed (Table 3 ).

Table (3): Distribution of patients and Pearson

Chi-aquare test in relation to the age group and presence of dry socket

\begin{tabular}{|c|c|c|c|c|}
\hline \multirow{2}{*}{ Age group (years) } & \multicolumn{4}{|c|}{ Dry socket } \\
\cline { 2 - 5 } & \multicolumn{2}{|c|}{ Present } & \multicolumn{2}{c|}{ Not present } \\
\cline { 2 - 5 } & No. & $\mathbf{\%}$ & No. & $\mathbf{\%}$ \\
\hline $\mathbf{( 1 3 - 1 9 )}$ & 3 & 15 & 17 & 85 \\
\hline $\mathbf{( 2 0 - 2 9 )}$ & 16 & 31.4 & 35 & 68.6 \\
\hline $\mathbf{( 3 0}-\mathbf{3 9 )}$ & 12 & 26.7 & 33 & 73.3 \\
\hline $\mathbf{( 4 0 - 4 9 )}$ & 6 & 20 & 24 & 80 \\
\hline $\mathbf{( 5 0 - 5 9 )}$ & 5 & 22.7 & 17 & 77.3 \\
\hline$(\geq \mathbf{6 0 )}$ & 3 & 25 & 9 & 75 \\
\hline Pearson $\chi^{2}=39.032, \mathrm{df}=48$.
\end{tabular}

The results of this study showed that the higher percentage of dry socket reduction was observed by the use of topical ibuprofen $(90.69 \%)$ followed by the use of topical metronidazole $(88 \%)$ compared with control -ve group (65.1\%) and control +ve group $(54.5 \%)$ which revealed the lowest percentage of reduction. Chisquare test showed a highly significant differences among the treatment groups as shown in Table (4).

Table (4): Chi-square test in relation to the abscence of dry socket in all treatment groups

\begin{tabular}{|c|c|c|c|}
\hline Group & Type of treatment & No. of patients & $\begin{array}{c}\text { No.(\%) of patients with no dry } \\
\text { socket }\end{array}$ \\
\hline I & No treatment (control -ve) & 43 & $28(65.1 \%)$ \\
\hline II & $\begin{array}{c}\text { Gelfoam alone (control } \\
+ \text { ve) }\end{array}$ & 44 & $24(54.5 \%)$ \\
\hline III & $\begin{array}{c}\text { Gelfoam with } \\
\text { metronidazole }\end{array}$ & 50 & $44(88 \%)$ \\
\hline IV & Gelfoam with ibuprofen & 43 & $39(90.69 \%)$ \\
\hline
\end{tabular}
$\chi^{2}=22.216, \mathrm{df}=3$.

\section{DISCUSSION}

Dry socket is one of the common complications following tooth extraction and is more common in posterior than in anterior teeth $^{(19-21)}$. Several methods have been advocated to reduce the incidence of dry socket including the use of antiseptic mouth washes, ${ }^{(22)}$ antifibrinolytic agents, ${ }^{(23)}$ antibiotics, ${ }^{(24)}$ steroids, clot supporting agents ${ }^{(19)}$ and other intra-alveolar dressings and medicaments. ${ }^{(25-26)}$

The results of this study showed that the prevalence of dry socket was $(25 \%)$ which is higher than that recorded by another investigators ${ }^{(27-28)}$ which stated that the percentage of dry socket may range between (4-24\%). This difference could be possibly attributed to the variarion in diagnostic criteria required by different researchers ( some of them adopted strict diagnostic criteria and therefore reported a lower incidence of dry socket) (27-29), whereas in our study a minimum of pain and empty socket with or without food 
debris were considered diagnostic, ${ }^{(19)}$ also the present study reflected the prevalence of this complication in lower posterior teeth only ( where the possibility of dry socket is more common due to more difficult extractions) compared with maxillary posterior teeth, upper and lower anterior teeth ${ }^{(30-31)}$. This could be due to more liberation of direct tissue activators secondary to bone marrow inflammation following more difficult and hence, more traumatic extractions ${ }^{(32)}$.

In this study, significant differences were observed between males (16.1\%) and females $(8.9 \%)$ as shown in Table (1). Although this is similar to the finding of AlKhateeb et al ${ }^{(20)}$, other studies ${ }^{(29,33)}$ reported a higher incidence in females, this could be explained by the fact that smoking habits in Western societies are almost identically distributed among both sexes, in addition most researchers who reported a higher incidence of dry socket in females concluded that the reason behind this high percentage is due to the excessive use of oral contraceptives ${ }^{(33,34)}$.

In regard to tooth number, the present study showed that the higher incidence of dry socket was noticed following lower third molar extraction (13.3\%), then lower second molar $(6.7 \%)$, while the least incidence was reported after first molar extraction ( $5 \%$ only), these findings were in agreement with other studies (33,35,36). Some authors still believe that increased bone density, decreased vascularity, and reduced capacity of producing granulation tissue around the socket of lower third molar are responsible for this site specificity $^{(29,32)}$ (Table 2).

Concerning age groups, the highest incidence of dry socket was found in the second and third decades (Table 3), yet no significant differences were noted among other groups. These findings were also reported by other investigators ${ }^{(19,27,33)}$. Although the reason for this age dependance is still unclear, the presence of well developed alveolar bone and the relative frequency of periodontal diseases at this age might provide a possible explanation $(33,35)$.

The use of gelfoam alone showed the highest incidence of dry socket compared to the remaining treatment groups (Table
4). This result was agreed by Suleiman ${ }^{(5)}$ who proved that the incidence of dry socket among gelfoam treated patients was significantly higher $(25 \%)$ than non-gelfoam treated patients $(6.0 \%)$, this material causes haemostasis by a physical mechanism rather than a chemical reaction, i.e. by compressing the blood vessels (but not influencing the clotting factors $)^{(7)}$. However, the high prevalence of dry socket in gelfoam treated patients was probably due to the continued chemical effect of the material which had been degraded and resorped slowly at the extraction site $e^{(37,38)}$. also gelfoam cause homeostasis and decrease blood flow and granulation tissue formation which cause dry socket.

The result of this study indicated that topical metronidazole reduced dry socket compared with control -ve and control $+\mathrm{ve}$ groups, this finding supported the claims of some authors ${ }^{(39-40)}$ about the role of anaerobic bacteria in the causation of dry socket. The rationale for using topical antibacterials was based on previous studies which stated that systemic metronidazole could significantly reduce the incidence of dry socket. ${ }^{(1,41)}$ The present study also demonstrated that the topical use of ibuprofen suspension showed a highly significant reduction in dry socket compared with the remaining treatment groups (Table 4). As the systemic ibuprofen have been used in the treatment of pain, swelling and other post operative complications after teeth extractions. ${ }^{(41)}$

Inflammation represents a complex series of physiologic reactions required for normal healing after physical injury or infection, mediators during evolution of the inflammatory process contribute to the genesis of acute pain by stimulating or sensitizing primary afferent neuron by peripheral and central mechanisms. The biochemical composition of the local environment of inflammed tissue is complex. Various biochemicals at the inflammation site affect nociceptive input by direct or indirect mechanisms, for example prostoglandins. The physiologic mechanism for the synthesis of prostoglandins is the activation of phospholipase A2, cyclooxygenase during the process of tissue damage ( as in tooth extraction procedure), this information has an important practical 
application by pretreating patients with non-steroidal anti inflammatory drugs before surgery. The rationale for this therapy is the blockage of enzymes before initiation of tissue damage. The advantage of pretreatment have been most clearly established for Ibuprofen ${ }^{(42)}$.

The topical use of ibuprofen suspension for the prevention of dry socket may be more beneficial than systemic route due to the following reasons:

1. Topical application is performed by the dentist so that its effect will be guaranteed, while systemic ibuprofen might need patient cooperation who may not use the drug at the proper time or the exact dose.

2. The concentration of ibuprofen suspension topically is greater than in case of systemic administration, this is because intestinal absorption may be reduced, while systemic use may causegastric

upset which may influence patient cooperation. In addition capillary thrombosis in the wall of the socket will reduce the concentration of ibuprofen reaching the clot after systemic administration.

3. When ibuprofen applied topically, the amount of ibuprofen absorped systemically will be less compared to systemic administration which will be more beneficial in hypertensive patient $^{(43)}$.

\section{CONCLUSIONS}

In conclusion, topical application of gelfoam impregnated with ibuprofen suspension significantly reduced the incidence of dry socket, followed by that of metronidazole suspension, while the topical application of gelfoam alone had increased the incidence of this complication. Males showed a significantly higher prevalence of dry socket than females. In addition, the hig-her percentage of dry socket was recorded after lower third molar removal.

\section{REFERENCES}

1. Reekie D, Downes P, Delvin GM, Nixon H. Prevention of dry socket with metronidazole. Br Dent J. 2005; 200:210-213.

2. Anand SC, Singh V, goel, Verma A,
Rai B. Dry socket an apriasal and surgical management. The Internet $J$ Dent Science. 2006; 4 (1): 1-5.

3. Metin M, Tek M, Senor I. Comparison of two chlorhexidine rinse protocols on the incidence of alveolar osteitis following the surgical removal of impacted third molars. J Contemp Dent Pract. 2006; 7(2): 079-086.

4. Schow SR. Evaluation of postoperative localized osteitis in mandibular third molar surgery. Oral Surg Oral Med Oral pathol. 1974; 38 : 352-358.

5. Suleiman AM. Influence of surgical gauze on the incidence of dry socket after wisdom tooth extraction. Eastern Mediterranean Health Journal. 2006; 24: 468-471.

6. Quinley JF. Dry socket after mandibular odontectomy and use of soluble tetracycline hydrochloride. Oral Surg Oral Med Oral pathol. 1960; 13: 38-42.

7. Birn H. Aetiology and pathogenesis of fibrinolytic alveolitis (Dry socket). Int J Oral Syrg. 1973; 2: 251-263

8. Sorenson DC, Preich JW. The effect of tetracycline on the incidence of post extraction alveolar osteitis. Journal of Oral and Mxillofacial surgery. 1987; 45: 1029-1033.

9. Oginni FO, Fatusi OA, Alagbe AO. A clinical evaluation of dry socket in a Nigerian teaching hospital. $J$ Oral and Mxillofac surg. 2003; 61(8): 871876.

10. Andra A, Ahrens HG, Schwerdtfeger K. Economic aspect of alveolitis. Stomatol-DDR. 1990; 40: 308-309.

11. Hermesch CB. Preoperative use of $0.12 \%$ chlorhexidine gluconate for the prevention of alveolar osteitis: eficacy and risk factors analysis. Oral Surg Oral Med Oral pathol Oral radiol endod.1998; 85(4): 381-387.

12. Trieger N, Schlagel GD. Preventing dry socket. A simple procedure that works. J Am Dent Aossoc. 1991; 122: 67-68.

13. Bloomer CR. Alveolar osteitis prevention by immediate placement of medicated packing. Oral Surg Oral Med Oral pathol Oral radiol endod. 2000; 90(3):282-284. 
14. Rood JP, Murgatroyd J. Metronidazole in the prevention of dry socket. $\mathrm{Br} \mathrm{J}$ Oral Surg. 1979; 17: 62-70.

15. Yoshii T. Differences in postoperative morbidity rates, including infection and dry socket, and differences in healing process after mandibular third molar surgery in patients receiving 1day or 3- day prophylaxis hith lenampicillin. $J$ Infect Chemother. 2002; 8 (1): 87-93

16. Caso A, Hung LK, Beirne OR. Prevention of alveolar osteitis with chlorhexidine: a meta-analytic review. Oral Surg Oral Med Oral pathol Oral radiol endod.2005; 99: 155-159..

17. Yagiela JA, Dowd FJ, Neidle EA. Pharmacology and Therapeutics for Dentistry. $5^{\text {th }}$ ed. The Elsevier Mosby Co. St Louis. 2004; 331-340.

18. Malamed SF. Handbook of Local Anesthesia. $5^{\text {th }}$ ed. The CV Mosby Co. St Louis. 2004; 193-219.

19. Blum IR. Contemporary views on dry socket ( alveolar osteitis): a clinical appraisal of standardization, aetiopathogenesis and management: a critical review. Int. J Oral Maxillofac Surg. 2002; 31: 309-317.

20. Al-Khateeb TL, El- Marsafi AL, Butler NP. The relationship between the indication for the surgical removal of impacted third molars and the incidence of alveolar osteitis. J Oral Maxillofac Surg. 1991; 49: 141-145.

21. Butler DP, Sweet JB. Effect of levage on the incidence of localized osteitis and mandibular third molar extraction sites. Oral Surg Oral Med Oral pathol. 1977; 44: 14-20.

22. Sweet JB, Macynaki AA, Effect of antimicrobial mouth rinse on the incidence of localized alveolitis and infection following mandibular third molar surgery. Oral Surg Oral Med Oral pathol. 1985; 59: 24-26.

23. Ritzau M, Swangs K. The priphylactic use of propylic ester of phydrobenzoic acid on alveolitis sicca dolorosa. Oral Surg Oral Med Oral pathol. 1977; 43: 32-37.

24. Rood JP, Murgatroid J. Metronidazole in the prevention of dry socket. $\mathrm{Br} J$ Oral Surg. 1979; 17: 62-70.

25. Poor MR, Hall JE, Poor AS. Reduc- tion in the incidence of alveolar osteitis in patient treated with the salicept patch, containing acemennan hydrogel. J Oral Maxillofac Surg. 2002; 60: 374-379.

26. Brown T. Dealing with dental disasters - a guide for community pharmacysts. Pharmaceutical J. 2007; 278: 561-564.

27. Amaratunga NA, Senaratne CM. A clinical study of dry socket in Srilanka. Br Jl Oral Maxillofac Surg. 1988; 26: 410-418.

28. Jaffar N,Nor GM. The percentage of post extraction complications in an outpatient dental clinic in Kuala Lumpor Malaysia- a retrospective survey. Singapore Dent J. 2000; 23(1): 24-28.

29. MacGregor AJ. Aetiology of dry socket: A clinical investigation. $\mathrm{Br} J$ Oral Surg. 1968; 6: 49-58.

30. Mansour MH, Cox SC. Patients presenting to the general practitioner with pain of dental origin. Med $J$ Aust. 2006; 185(2): 64-68.

31. Larsen PE. The effect of a chlorhexidine rinse on the incidence of alveolar osteitis following the surgical removal of impacted mandibular third molars. $J$ Oral Maxillofac Surgery. 1991; 49: 932-937.

32. Brin H. Aetiology and pathogenesis of fibrinolytic alveolitis (dry socket). Int J Oral Surg. 1973; 2: 215-263.

33. Field EA, Speechly JA, Rotter E, Scott J. Dry socket incidence compared after a 12- year interval. Br J Oral Maxillofac Surg. 1985; 23: 419-427.

34. Garcia AG, Grana OM, Sampedro FG, Diago MP, Rey JM . Does oral contraceptive use affect the incidence of complications after extraction of mandibular third molars. Br Dent J. 2003; 194: 453-455.

35. Nussir YM, Younis MH. Prevalence, clinical picture, and risk factors of dry socket in a Jordanian Dental teaching center. J Contemp Dent Pract. 2007; 8 (3): 1-14.

36. Oginni FO, Fatusi OA, Alagbe AO. A clinical evaluation of dry socket in a Nigerian teaching hospital. $J$ Oral Maxillofac Surg. 2003; 61 (8): 871876.

37. Singh M. Potential biosoluble carriers; 
biocompatibility and biodegradability of oxidized cellulose. Biomat Med Device Artificial Organs. 1997; 7(4): 495-512.

38. Voormolen JH. Haemostatic agents: brain tissue reaction and effectiveness. A comparative animal study using collagen fleece and oxidized cellulose. J Neurosurgery. 1987; 20(5): 702-

39. BOQwn LR, Merrill SS, Allen RE. Microbiologic study of intra oral wounds. J Oral Surg. 1970; 28: 89-95.

40. Hamad SA. Clinical evaluation of topical tetracycline, metronidazole and chlorhexidine for the prevention of dry socket after surgical removal of impacted lower third molars. M Sc thesis. College of Dentistry. University of
Mosul. 1997.

41. Bjornsson GA, Hanaes HR, Skoylund LA. A randomized, double- blind crossover trial of paracetamol 1000 mg four times daily vs ibuprofen 600 mg: effect on swelling and other postoperative events after third molar surgery. Br J Clin Pharmacol. 2003; 55: 405-412.

42. Jackson DL, Moore PA, Hargreaves KM. Preoperative nonsteroidal antiinflammatory medication for the prevention of postoperative dental pain. $J$ Am Dent Assoc. 1989; 119: 641-647.

43. Wagner W, Khanna P, Furst DE. Katzung BG. Basic and Clinical Pharmacology. $9^{\text {th }}$ ed. The McrawHill Companies. 2004; 576-603. 